\title{
Improvement in the Power Conversion Efficiency of Bulk Heterojunction Photovoltaic Device via Thermal Postannealing of Subphthalocyanine: $\mathrm{C}_{70}$ Active Layer
}

\author{
Chih-Chien Lee, ${ }^{1}$ Shun-Wei Liu, ${ }^{2}$ Ching-Wen Cheng, ${ }^{1}$ Wei-Cheng Su, ${ }^{1}$ \\ Chia-Chang Chou, ${ }^{1}$ Chun-Feng Lin, ${ }^{2}$ and Chin-Ti Chen ${ }^{3}$ \\ ${ }^{1}$ Department of Electronic Engineering, National Taiwan University of Science and Technology, Taipei 10607, Taiwan \\ ${ }^{2}$ Department of Electronic Engineering, Ming Chi University of Technology, New Taipei City 24301, Taiwan \\ ${ }^{3}$ Institute of Chemistry, Academia Sinica, Taipei 11529, Taiwan
}

Correspondence should be addressed to Shun-Wei Liu; swliu@mail.mcut.edu.tw

Received 4 January 2013; Accepted 4 June 2013

Academic Editor: Liang-Sheng Liao

Copyright (C) 2013 Chih-Chien Lee et al. This is an open access article distributed under the Creative Commons Attribution License, which permits unrestricted use, distribution, and reproduction in any medium, provided the original work is properly cited.

\begin{abstract}
The authors report an efficient organic photovoltaic device based on subphthalocyanine ( $\mathrm{SubPc})$ : $\mathrm{C}_{70}$ bulk heterojunction (BHJ) via the postannealing treatment. The power conversion efficiency is improved from $4.5 \%$ to $5.5 \%$ due to the increase in short-circuit current density $\left(J_{\mathrm{SC}}\right)$ from 8.8 to $12.7 \mathrm{~mA} / \mathrm{cm}^{2}$ with the expense of decreased fill factor from $52 \%$ to $42 \%$. From external quantum efficiency measurements, the spectral shape-independent enhancement over the entire spectrum suggests that the increased $J_{\mathrm{SC}}$ mainly originates from improved charge collection efficiency. To confirm this inference, the hole and electron mobilities in the $\mathrm{BHJ}$ are estimated from the space-charge limited current, showing improved transport properties at the optimum temperature. Moreover, the morphologic change is also studied as a function of annealing temperature. A larger grain size is observed with increasing temperature due to the phase separation of SubPc and $\mathrm{C}_{70}$. However, at higher temperatures the strong aggregation of $\mathrm{C}_{70}$ molecules may interrupt the pathway of SubPc, resulting in hindered charge transport and, hence, reduced $J_{\mathrm{SC}}$.
\end{abstract}

\section{Introduction}

Organic photovoltaic (OPV) devices show great potential for commercialization in this decade, due to the huge progress in power conversion efficiency [1]. In addition, the capability of flexible manufacturing processes promotes the versatility of OPV devices [2]. In principle, OPV devices could be sorted by photoactive material, into polymer-based and small molecular systems [3-5]. A polymer-based OPV device is usually fabricated using the solution process, which enables the blend of the donor and acceptor to form the interpenetrating network for the large dissociation area [5]. With morphological manipulation through the annealing treatment, the phase separation of donor and acceptor can be controlled to enhance the extraction of photocurrent $[6,7]$. Thus, high power conversion efficiencies (PCEs) of more than $6 \%$ have been reported extensively in the recent years [811]. In contrast, the efficiency of small molecule OPV devices is much lower compared with their polymeric counterparts, particularly with regard to the short-circuit current density $\left(J_{\mathrm{SC}}\right)$, due to the smaller interfacial area between the donor and acceptor in the planar heterojunction, usually seen in thermal evaporation systems [12-14]. Therefore, employing bulk heterojunction in small molecular OPV devices is required for high performance of the devices.

Several research works have successfully shown significant improvement in photocurrent with the bulk heterojunction structure using conventional donors [15-18]. Moreover, the annealing treatment is also extensively performed to enhance the efficiency of the device. Peumans and his coworkers suggested that the phase separation between donor and acceptor could be controlled under the annealing treatment [19]. Sakai and his colleagues observed the considerable increase in all operating parameters in bulk heterojunction devices after the annealing treatment [20]. They attributed the enhancement to the improved charge transport property 

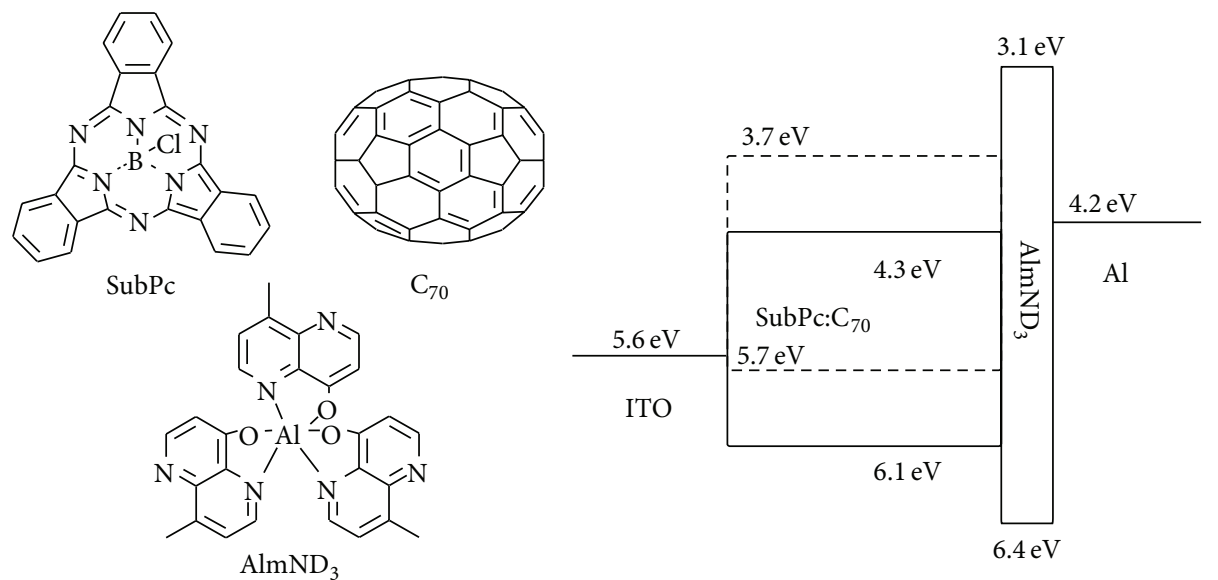

FIgURE 1: Chemical structures of SubPc, $\mathrm{C}_{70}, \mathrm{AlmND}_{3}$, and their energy level alignments in OPVs.

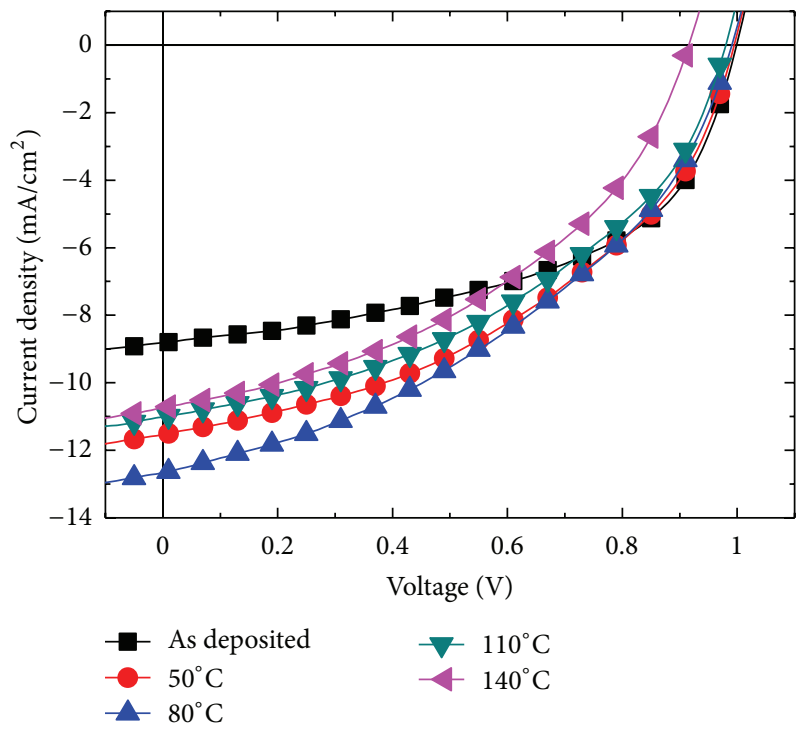

Figure 2: The $J-V$ characteristics under the AM $1.5 \mathrm{G}$ solar illumination for the devices with different annealing temperatures.

due to the increased molecular packing density. Wei et al. identified the high dependence of the annealing process on the device performance [21]. Upon increasing the annealing temperature, the $J_{\mathrm{SC}}$ can be enhanced by about $20 \%$, leading to higher performance. Wagner et al. studied the morphology as a function of annealing temperature [22]. They found clear phase separation of the mixing layer during the annealing process. The previous research works have shown the potential use of bulk heterojunction in small molecule OPV devices and the additional annealing treatment necessary to achieve a highly efficient device. In this text, we have fabricated a highly efficient bulk heterojunction OPV device by using the postannealing treatment. Due to the phase separation of donor and acceptor during the annealing process, the carrier mobility could be significantly improved and lead to enhanced photocurrent. The morphological change in thin films with different annealing temperatures further confirms the origin of the increased carrier mobility due to the emergence of the larger grains as the temperature increases.

\section{Experimental Methods}

The device structure used in this report, as shown in Figure 1, is indium tin oxide (ITO)/subphthalocyanine (SubPc): $\mathrm{C}_{70}$ in $1: 2$ weight ratio $(50 \mathrm{~nm}) /$ tris (4-hydroxy-8-methyl-1,5naphthyridinate) aluminium $\left(\mathrm{AlmND}_{3}\right)(10 \mathrm{~nm}) / \mathrm{Al}$, where $\mathrm{AlmND}_{3}$ serves as buffer layer [23]. Such an optimal mixed ratio of the active layer is thoroughly studied in other works. The ITO substrates were cleaned by solvent sonication and surface subjected to treatment with oxygen plasma prior to use. The deposition of organic and metal layers was done in a high vacuum $\left(8 \times 10^{-6}\right.$ Torr $)$ chamber. Before the deposition of buffer layer, the samples were heated on a homemade holder at four temperatures: $50^{\circ} \mathrm{C}, 80^{\circ} \mathrm{C}, 110^{\circ} \mathrm{C}$, and $140^{\circ} \mathrm{C}$. The devices were completed with deposition of $\mathrm{Al}$ through a shadow mask to define the active area of $0.04 \mathrm{~cm}^{2}$ and well encapsulated to isolate ambient influences. Device performance was assessed in open air. The current densityvoltage $(J-V)$ characteristics in the dark and under air mass (AM) $1.5 \mathrm{G}$ solar illumination from a solar simulator (Newport 91160A) were determined using a source meter (Keithley 2400). The intensity of solar illumination was calibrated with Si reference cell (PV measurement, area: $\left.3.981 \mathrm{~cm}^{2}\right)$. For the external quantum efficiency (EQE) measurement, a monochromator (Newport 74100) was used to select the wavelength from 350 to $800 \mathrm{~nm}$. The photocurrent from the devices upon illumination was collected using a lock-in amplifier (Signal Recovery 7265), which was chopped at $250 \mathrm{~Hz}$ with a chopper. The mobility of holes and electrons with different temperature treatment was estimated from the space-charge limited current (SCLC) with hole- and electrononly devices. The atomic force microscopic (AFM) images were taken with a Park System XE-100 using the noncontact mode and cantilever frequency of $320 \mathrm{kHz}$.

\section{Results and Discussion}

Figure 2 shows the $J-V$ characteristics of the OPV devices with different annealing treatments under AM $1.5 \mathrm{G}$ solar 


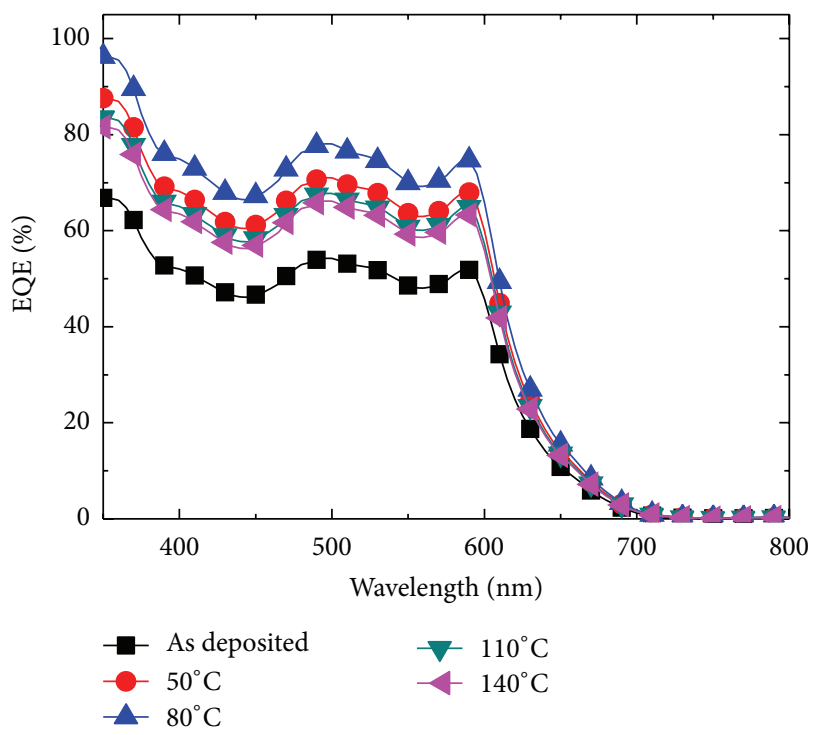

(a)

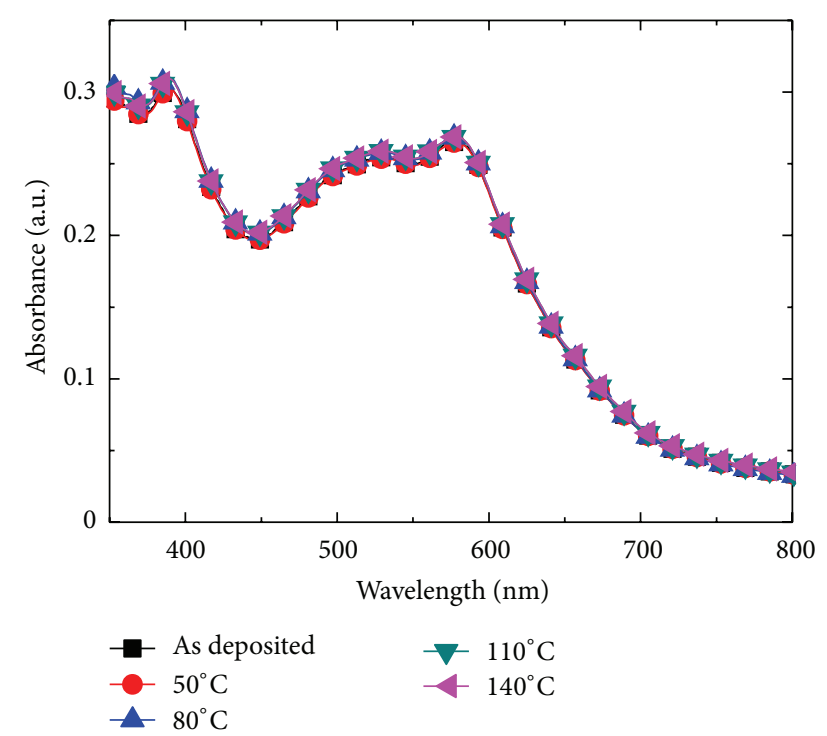

(b)

FIGURE 3: (a) The EQE and (b) absorption spectra of the OPV devices with various postannealing temperatures.

illumination. The photovoltaic parameters are summarized in Table 1. For the device annealed at $140^{\circ} \mathrm{C}$, the $V_{\mathrm{OC}}$ is significantly decreased to $0.92 \mathrm{~V}$ compared with the other devices, which registered about $1 \mathrm{~V}$. The $J_{\mathrm{SC}}$ is enhanced from 8.8 to $12.7 \mathrm{~mA} / \mathrm{cm}^{2}$ and then reduced to $10.7 \mathrm{~mA} / \mathrm{cm}^{2}$ as the annealing temperature increases. The device without treatment shows the highest FF at 52\%, while this is considerably decreased after the annealing process. Consequently, the highest PCE of $5.5 \%$ is obtained when using the $80^{\circ} \mathrm{C}$ annealing due to the substantial enhancement in $J_{\mathrm{SC}}$, which is similar to the polymeric system $[24,25]$. This is attributed to the critical balance between the phase separation and the charge collection efficiency. The temperature-dependent $V_{\text {OC }}$ was also observed in the previous results, which explained this phenomenon using the AFM images [26]. The formation of the island-like morphology at high temperatures due to a high degree of phase separation may cause the enhanced recombination at opposing electric fields, leading to the reduced built-in potential and, hence, the $V_{\text {OC }}$. As a result, temperature annealing tends to increase the phase separation in the mixed layer, leading to the decrease in $V_{\text {OC }}$ with temperature.

In order to clarify the origin of the significant enhancement in $J_{S C}$, the EQE is measured as shown in Figure 3(a). The contribution from the absorption property is excluded due to the changeless absorption spectra for all thin films with different annealing temperatures as indicated in Figure 3(b). A large change is observed in EQE over the entire spectrum dependent on the annealing temperature. However, the spectral shape remains the same for all devices. This indicates that the enhanced $J_{\mathrm{SC}}$ is mainly due to the improved charge collection efficiency, rather than increased light harvesting from either SubPc or $\mathrm{C}_{70}$, as expected due to the changeless absorption spectra $[27,28]$. For most polymeric cases, the postannealing process can improve the crystallinity of the thin film and enhance the carrier mobility [29]. A few studies of OPV devices have shown that better molecular packing during the annealing treatment can lead to increased mobility and, hence, the device performance [21, 30-32]. In our case, the enhanced charge collection efficiency is ascribed to the improved crystallinity after the postannealing. Beyond the optimized temperature, the large phase separation may completely separate the donor and acceptor, resulting in hindered charge transport and a decrease in the $J_{\text {SC }}$.

Hole- and electron-only devices consisting of ITO/ SubPc: $\mathrm{C}_{70}(150 \mathrm{~nm}) / \mathrm{Au}$ and $\mathrm{Al} / \mathrm{SubPc}: \mathrm{C}_{70}(150 \mathrm{~nm}) / \mathrm{Al}$ were used to investigate the electrical property of the mixing layer. The temperature-dependent carrier mobility for hole and electron is shown in Figure 4(a). Figures 4(b) and 4(c) are the corresponding $J-V$ characteristics of hole- and electron-only devices. The estimated mobility from the SCLC is indicated in Table 1 according to the following equation $[33,34]$ :

$$
J_{\text {SCLC }}=\frac{9}{8} \mu \varepsilon \frac{E^{2}}{L},
$$

where $\mu$ is the carrier mobility, $\varepsilon$ is the permittivity of the thin film (4.4 for our mixing layer using the concentrationdependent dielectric constant from [35]), $E$ is the electric field across the device, and $L$ is the entire thin film thickness. For electron mobility, a monotonic increase is obtained. It can be attributed to the phase aggregation of $\mathrm{C}_{70}$ molecules as the annealing temperature increases. Nevertheless, the hole mobility initially increases from room temperature to $80^{\circ} \mathrm{C}$ and then decreases at higher temperatures. This is consistent with the speculation about the large aggregation of $\mathrm{C}_{70}$ molecules that hinders the hole transport at high temperatures [36-38]. The highest hole mobility is obtained at $80^{\circ} \mathrm{C}$, which correspondingly gives the highest $J_{\mathrm{SC}}$ in the OPV devices, due to the significantly improved charge transport. However, the best charge balance condition at the 


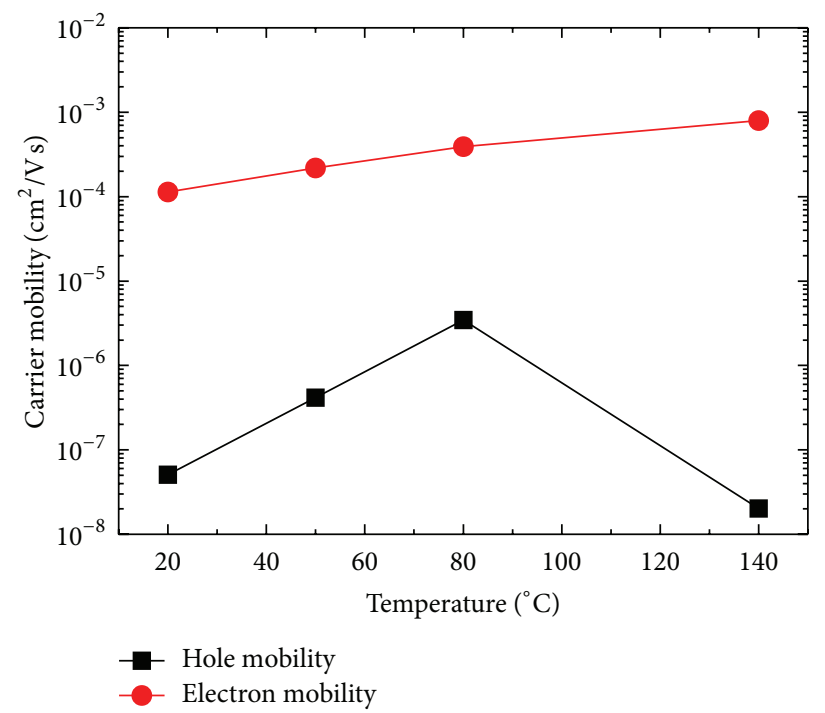

(a)

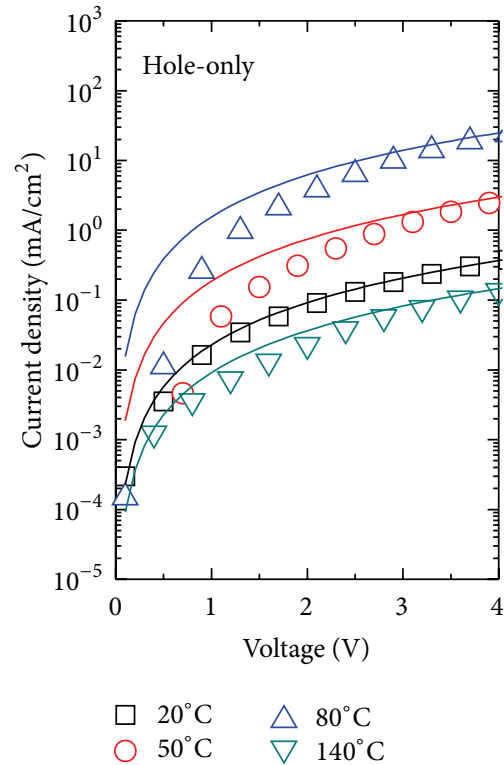

(b)

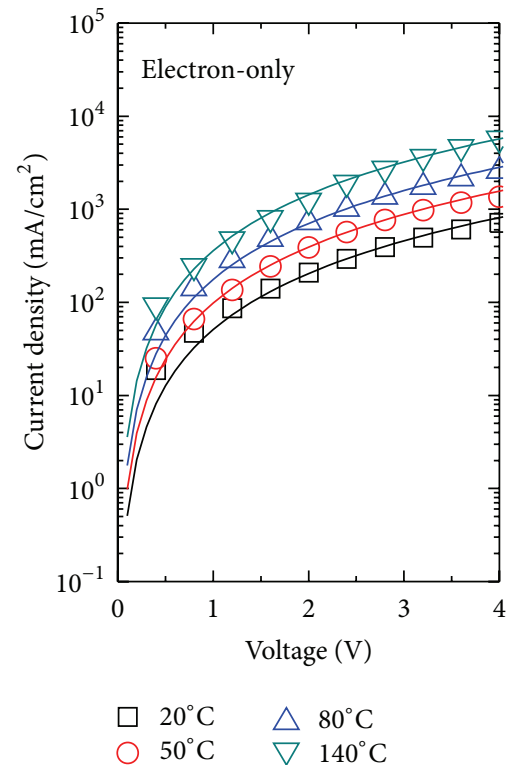

(c)

Figure 4: (a) The hole and electron mobilities of the active layer of SubPc: $\mathrm{C}_{70}$ with various postannealing temperatures. The corresponding $J$ - $V$ data for (b) hole- and (c) electron-only devices with solid lines as the fitting results of the SCLC.

TABLE 1: The photovoltaic performance under AM 1.5 G solar illumination and the respective hole and electron mobilities estimated from SCLC.

\begin{tabular}{|c|c|c|c|c|c|c|}
\hline Device & $V_{\mathrm{OC}}(\mathrm{V})$ & $J_{\mathrm{SC}}\left(\mathrm{mA} / \mathrm{cm}^{2}\right)$ & $\mathrm{FF}(\%)$ & PCE (\%) & $\mu_{h}\left(\mathrm{~cm}^{2} / \mathrm{Vs}\right)$ & $\mu_{e}\left(\mathrm{~cm}^{2} / \mathrm{Vs}\right)$ \\
\hline As deposited & 1.00 & 8.8 & 52 & 4.6 & $5.1 \times 10^{-8}$ & $1.1 \times 10^{-4}$ \\
\hline $50^{\circ} \mathrm{C}$ & 0.99 & 11.5 & 45 & 5.1 & $4.2 \times 10^{-7}$ & $2.2 \times 10^{-4}$ \\
\hline $80^{\circ} \mathrm{C}$ & 0.99 & 12.7 & 44 & 5.5 & $3.4 \times 10^{-6}$ & $3.9 \times 10^{-4}$ \\
\hline $110^{\circ} \mathrm{C}$ & 0.98 & 11.0 & 44 & 4.7 & - & - \\
\hline $140^{\circ} \mathrm{C}$ & 0.92 & 10.7 & 42 & 4.1 & $2.0 \times 10^{-8}$ & $7.9 \times 10^{-4}$ \\
\hline
\end{tabular}




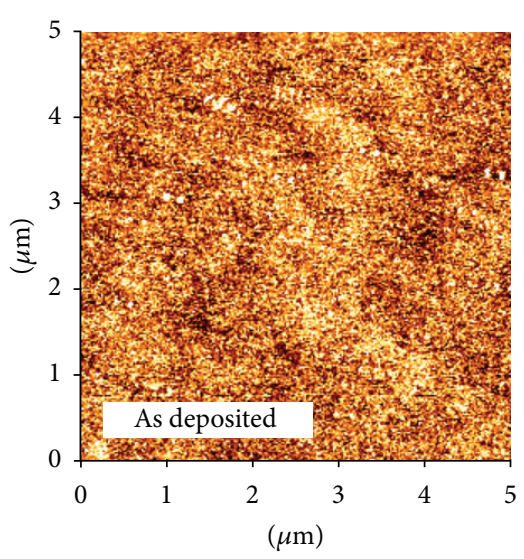

(a)

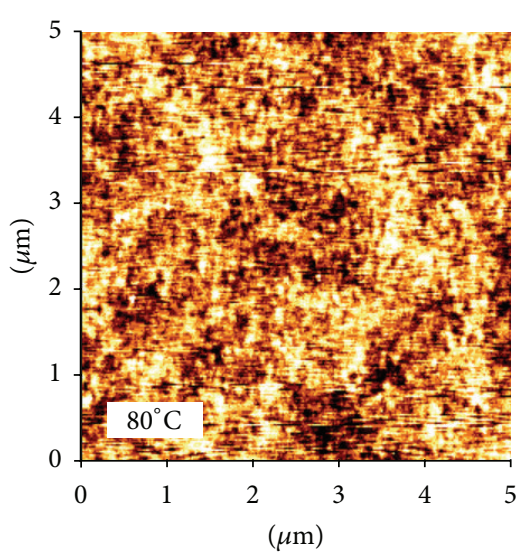

(b)

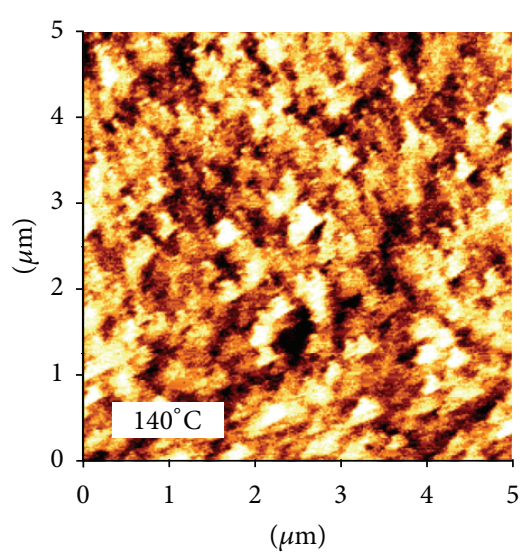

(c)

FIGURE 5: The AFM images for the active layer of SubPc: $\mathrm{C}_{70}$ with various postannealing temperatures.

optimum temperature may facilitate the extraction of carriers and in turn achieve a high charge collection efficiency, as in the earlier reports $[18,39,40]$.

The morphological change because of the annealing temperature is examined by AFM images, as shown in Figure 5. Thin film, as deposited without any treatment, exhibits a rather smooth surface. After performing the annealing at $80^{\circ} \mathrm{C}$, the surface of the thin film becomes rougher, indicating that phase separation occurs between the SubPc and $\mathrm{C}_{70}$. When the annealing temperature is $140^{\circ} \mathrm{C}$, the larger grains emerge due to the significant phase separation of SubPc and $\mathrm{C}_{70}$. Similar results have been shown in the polymeric systems $[25,41]$. Through increasing the annealing temperature, the improved carrier mobility of the hole and electron is ascribed to the enhanced crystallinity of SubPc and $\mathrm{C}_{70}$ within the mixed layer. The high degree of phase aggregation in the $140^{\circ} \mathrm{C}$-annealed thin film is attributed to the strong aggregation of $\mathrm{C}_{70}$. From the SCLC measurement, the significant decrease in hole mobility under high temperatures originates from the disconnection of the SubPc pathway. The hindered SubPc pathway is likely due to the strong phase aggregation of $\mathrm{C}_{70}$. Therefore, these results suggest that there is a critical balance between the phase separation and the charge collection efficiency for improved performance of the device.

\section{Conclusion}

In conclusion, we have demonstrated an efficient OPV device using postannealing treatment. A significant increase in $J_{\mathrm{SC}}$ was observed and led to an improved PCE from $4.6 \%$ to $5.5 \%$. The spectral shape-dependent increase in EQE over the entire spectrum indicated that the increased $J_{S C}$ came from the improved charge collection efficiency rather than the light harvesting. From the SCLC result, the best charge balance condition as well as the substantial enhancement in carrier mobility at the optimum annealing temperature contributes to the highest photocurrent. Moreover, the effects of annealing on the morphology were also investigated by AFM images. They showed growth of larger-sized grains as the temperature increased, which may be due to the phase separation of SubPc and $\mathrm{C}_{70}$. Therefore, it is believed that the critical tradeoff between the phase separation and charge collection efficiency plays an important role in improving the device performance.

\section{Acknowledgments}

The authors acknowledge the Academia Sinica of Taiwan and the financial support from the National Science Council (Grant nos. NSC 102-3113-E-001-001, NSC 101-2221-E-131025, NSC 101-2627-E-002-005, and NSC 101-2221-E-011-120). In addition, S.-W. Liu specially thanks Mr. Ted Kao, Uchi Optoelectronic (Malaysia) Sdn. Bhd., for the donation of research equipment (Flexible Optoelectronic Device and Processing Laboratory, MCUT).

\section{References}

[1] A. Mishra and P. Bäuerle, "Small molecule organic semiconductors on the move: promises for future solar energy technology," Angewandte Chemie, vol. 51, no. 9, pp. 2020-2067, 2012.

[2] J. Jensen, H. F. Dam, J. R. Reynolds, A. L. Dyer, and F. C. Krebs, "Manufacture and demonstration of organic photovoltaicpowered electrochromic displays using roll coating methods and printable electrolytes," Journal of Polymer Science B, vol. 50, no. 8, pp. 536-545, 2012.

[3] B. Kippelen and J.-L. Brédas, "Organic photovoltaics," Energy \& Environmental Science, vol. 2, no. 3, pp. 251-261, 2009.

[4] C. Deibel and V. Dyakonov, "Polymer-fullerene bulk heterojunction solar cells," Reports on Progress in Physics, vol. 73, no. 9, Article ID 096401, 2010.

[5] P. Sonar, J. P. Fong Lim, and K. L. Chan, "Organic non-fullerene acceptors for organic photovoltaics," Energy \& Environmental Science, vol. 4, no. 5, pp. 1558-1574, 2011.

[6] L.-M. Chen, Z. Hong, G. Li, and Y. Yang, "Recent progress in polymer solar cells: manipulation of polymer: fullerene morphology and the formation of efficient inverted polymer solar cells," Advanced Materials, vol. 21, no. 14-15, pp. 1434-1449, 2009.

[7] B. Ray, P. R. Nair, and M. A. Alam, "Annealing dependent performance of organic bulk-heterojunction solar cells: a theoretical perspective," Solar Energy Materials and Solar Cells, vol. 95, no. 12, pp. 3287-3294, 2011. 
[8] H.-Y. Chen, J. Hou, S. Zhang et al., "Polymer solar cells with enhanced open-circuit voltage and efficiency," Nature Photonics, vol. 3, no. 11, pp. 649-653, 2009.

[9] Y. Liang, Z. Xu, J. Xia et al., "For the bright future-bulk heterojunction polymer solar cells with power conversion efficiency of 7.4\%," Advanced Materials, vol. 22, no. 20, pp. E135-E138, 2010.

[10] T.-Y. Chu, J. Lu, S. Beaupré et al., "Bulk heterojunction solar cells using thieno[3,4-c]pyrrole-4,6-dione and dithieno[3,2-b:2', $3^{\prime}$ d] silole copolymer with a power conversion efficiency of $7.3 \%$," Journal of the American Chemical Society, vol. 133, no. 12, pp. 4250-4253, 2011.

[11] S. C. Price, A. C. Stuart, L. Yang, H. Zhou, and W. You, "Fluorine substituted conjugated polymer of medium band gap yields $7 \%$ efficiency in polymer-fullerene solar cells," Journal of the American Chemical Society, vol. 133, no. 12, pp. 4625-4631, 2011.

[12] A. P. Yuen, N. M. Bamsey, A.-M. Hor et al., "Rubrene as an additive in M-phthalocyanine/fullerene organic solar cells," Solar Energy Materials and Solar Cells, vol. 95, no. 11, pp. 3137-3141, 2011.

[13] M. Ghasemi Varnamkhasti, H. R. Fallah, M. Mostajaboddavati, R. Ghasemi, and A. Hassanzadeh, "Comparison of metal oxides as anode buffer layer for small molecule organic photovoltaic cells," Solar Energy Materials and Solar Cells, vol. 98, pp. 379384, 2012.

[14] S. Zhong, J. Q. Zhong, X. Z. Wang et al., "Investigation of interface properties for ClAlPc/C60 heterojunction-based inverted organic solar cell," The Journal of Physical Chemistry C, vol. 116, no. 3, pp. 2521-2526, 2012.

[15] T. W. Ng, M. F. Lo, M. K. Fung et al., "Electronic properties and open-circuit voltage enhancement in mixed copper phthalocyanine: fullerene bulk heterojunction photovoltaic devices," Applied Physics Letters, vol. 95, no. 20, Article ID 203303, 3 pages, 2009.

[16] J. Sakai, T. Taima, T. Yamanari, Y. Yoshida, A. Fujii, and M. Ozaki, "Pentacene: fullerene multilayer-heterojunction organic photovoltaic cells fabricated by alternating evaporation method," Japanese Journal of Applied Physics, vol. 49, no. 3, Article ID 032301, 7 pages, 2010.

[17] J. Meiss, A. Merten, M. Hein et al., "Fluorinated zinc phthalocyanine as donor for efficient vacuum-deposited organic solar cells," Advanced Functional Materials, vol. 22, no. 2, pp. 405-414, 2012.

[18] R. Pandey, A. A. Gunawan, K. A. Mkhoyan, and R. J. Holmes, "Efficient organic photovoltaic cells based on nanocrystalline mixtures of boron subphthalocyanine chloride and $\mathrm{C}_{60}$," Advanced Functional Materials, vol. 22, no. 3, pp. 617-624, 2012.

[19] P. Peumans, S. Uchida, and S. R. Forrest, "Efficient bulk heterojunction photovoltaic cells using small-molecular-weight organic thin films," Nature, vol. 425, no. 6954, pp. 158-162, 2003.

[20] J. Sakai, T. Taima, T. Yamanari, and K. Saito, "Annealing effect in the sexithiophene: $\mathrm{C}_{70}$ small molecule bulk heterojunction organic photovoltaic cells," Solar Energy Materials and Solar Cells, vol. 93, no. 6-7, pp. 1149-1153, 2009.

[21] G. Wei, R. R. Lunt, K. Sun, S. Wang, M. E. Thompson, and S. R. Forrest, "Efficient, ordered bulk heterojunction nanocrystalline solar cells by annealing of ultrathin squaraine thin films," Nano Letters, vol. 10, no. 9, pp. 3555-3559, 2010.

[22] J. Wagner, M. Gruber, A. Hinderhofer et al., "High fill factor and open circuit voltage in organic photovoltaic cells with diindenoperylene as donor material," Advanced Functional Materials, vol. 20, no. 24, pp. 4295-4303, 2010.
[23] S.-W. Liu, C.-C. Lee, C.-F. Lin, J.-C. Huang, C.-T. Chen, and J.-H. Lee, "4-Hydroxy-8-methyl-1,5-naphthyridine aluminium chelate: a morphologically stable and efficient exciton-blocking material for organic photovoltaics with prolonged lifetime," Journal of Materials Chemistry, vol. 20, no. 36, pp. 7800-7806, 2010.

[24] F. Padinger, R. S. Rittberger, and N. S. Sariciftci, "Effects of postproduction treatment on plastic solar cells," Advanced Functional Materials, vol. 13, no. 1, pp. 85-88, 2003.

[25] G. Li, V. Shrotriya, Y. Yao, and Y. Yang, "Investigation of annealing effects and film thickness dependence of polymer solar cells based on poly(3-hexylthiophene)," Journal of Applied Physics, vol. 98, no. 4, Article ID 043704, 5 pages, 2005.

[26] M. Vogel, J. Strotmann, B. Johnev, M. C. Lux-Steiner, and K. Fostiropoulos, "Influence of nanoscale morphology in small molecule organic solar cells," Thin Solid Films, vol. 511-512, pp. 367-370, 2006.

[27] Y. Zhao, Z. Xie, C. Qin, Y. Qu, Y. Geng, and L. Wang, "Enhanced charge collection in polymer photovoltaic cells by using an ethanol-soluble conjugated polyfluorene as cathode buffer layer," Solar Energy Materials and Solar Cells, vol. 93, no. 5, pp. 604-608, 2009.

[28] R. Pandey and R. J. Holmes, "Characterizing the charge collection efficiency in bulk heterojunction organic photovoltaic cells," Applied Physics Letters, vol. 100, no. 8, Article ID 083303, 3 pages, 2012.

[29] R. A. J. Janssen, J. C. Hummelen, and N. S. Sariciftci, "Polymerfullerene bulk heterojunction solar cells," MRS Bulletin, vol. 30, no. 1, pp. 33-36, 2005.

[30] A. C. Mayer, M. T. Lloyd, D. J. Herman, T. G. Kasen, and G. G. Malliaras, "Postfabrication annealing of pentacene-based photovoltaic cells," Applied Physics Letters, vol. 85, no. 25, pp. 6272-6274, 2004.

[31] G. D. Sharma, P. Suresh, and J. A. Mikroyannidis, "Effect of thermal annealing and incorporating $\mathrm{TiO}_{2}$ layer on the photovoltaic performance of single- and bi-layer bulk heterojunction devices based on phenylenevinylene copolymer and small molecule," Organic Electronics, vol. 11, no. 5, pp. 731-742, 2010.

[32] M. Shin, H. Kim, J. Park et al., "Abrupt morphology change upon thermal annealing in poly(3-hexylthiophene)/soluble fullerene blend films for polymer solar cells," Advanced Functional Materials, vol. 20, no. 5, pp. 748-754, 2010.

[33] T.-Y. Chu and O.-K. Song, "Hole mobility of $N, N^{\prime}$ bis(naphthalen-1-yl)- $N, N^{\prime}$-bis(phenyl) benzidine investigated by using space-charge-limited currents," Applied Physics Letters, vol. 90, no. 20, Article ID 203512, 3 pages, 2007.

[34] M. A. Khan, W. Xu, H. Khizar ul et al., "Electron mobility of 4,7-diphyenyl-1,10-phenanthroline estimated by using spacecharge-limited currents," Journal of Applied Physics, vol. 103, no. 1, Article ID 014509, 4 pages, 2008.

[35] H. Looyenga, "Dielectric constants of heterogeneous mixtures," Physica, vol. 31, no. 3, pp. 401-406, 1965.

[36] J. K. J. van Duren, X. Yang, J. Loos et al., "Relating the morphology of poly(p-phenylene vinylene)/ methanofullerene blends to solar-cell performance," Advanced Functional Materials, vol. 14, no. 5, pp. 425-434, 2004.

[37] J. Huang, G. Li, and Y. Yang, "Influence of composition and heat-treatment on the charge transport properties of poly(3hexylthiophene) and [6,6]-phenyl $\mathrm{C}_{61}$-butyric acid methyl ester blends," Applied Physics Letters, vol. 87, no. 11, 3 pages, 2005.

[38] W.-H. Baek, T.-S. Yoon, H. H. Lee, and Y.-S. Kim, "Composition-dependent phase separation of P3HT:PCBM composites 
for high performance organic solar cells," Organic Electronicss, vol. 11, no. 5, pp. 933-937, 2010.

[39] G. Li, V. Shrotriya, J. Huang et al., "High-efficiency solution processable polymer photovoltaic cells by self-organization of polymer blends," Nature Materials, vol. 4, no. 11, pp. 864-868, 2005.

[40] V. D. Mihailetchi, H. X. Xie, B. de Boer, L. J. A. Koster, and P. W. M. Blom, "Charge transport and photocurrent generation in poly(3-hexylthiophene): methanofullerene bulkheterojunction solar cells," Advanced Functional Materials, vol. 16, no. 5, pp. 699-708, 2006.

[41] S. K. Park, Y.-H. Kim, and J.-I. Han, "Effect of annealing treatment and surface morphology on power conversion in organic photovoltaics," Japanese Journal of Applied Physics, vol. 48, no. 8, Article ID 081505, 3 pages, 2009. 

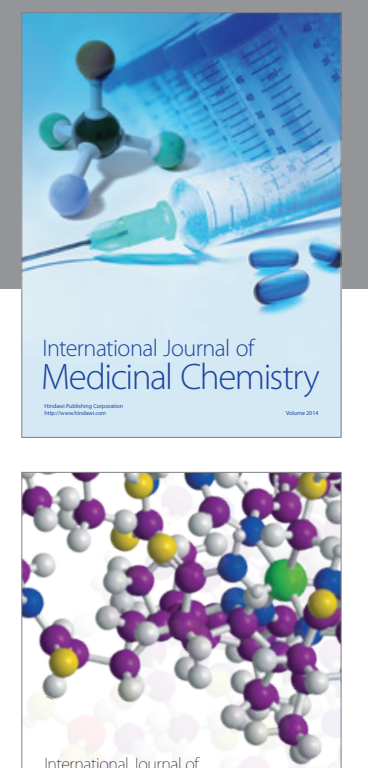

\section{Carbohydrate} Chemistry

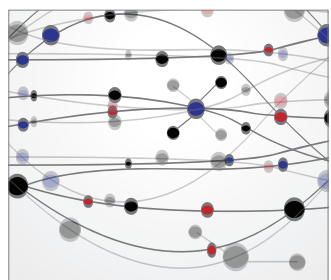

The Scientific World Journal
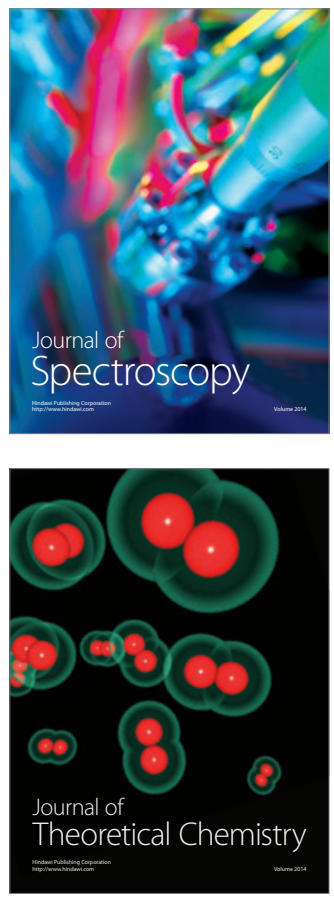
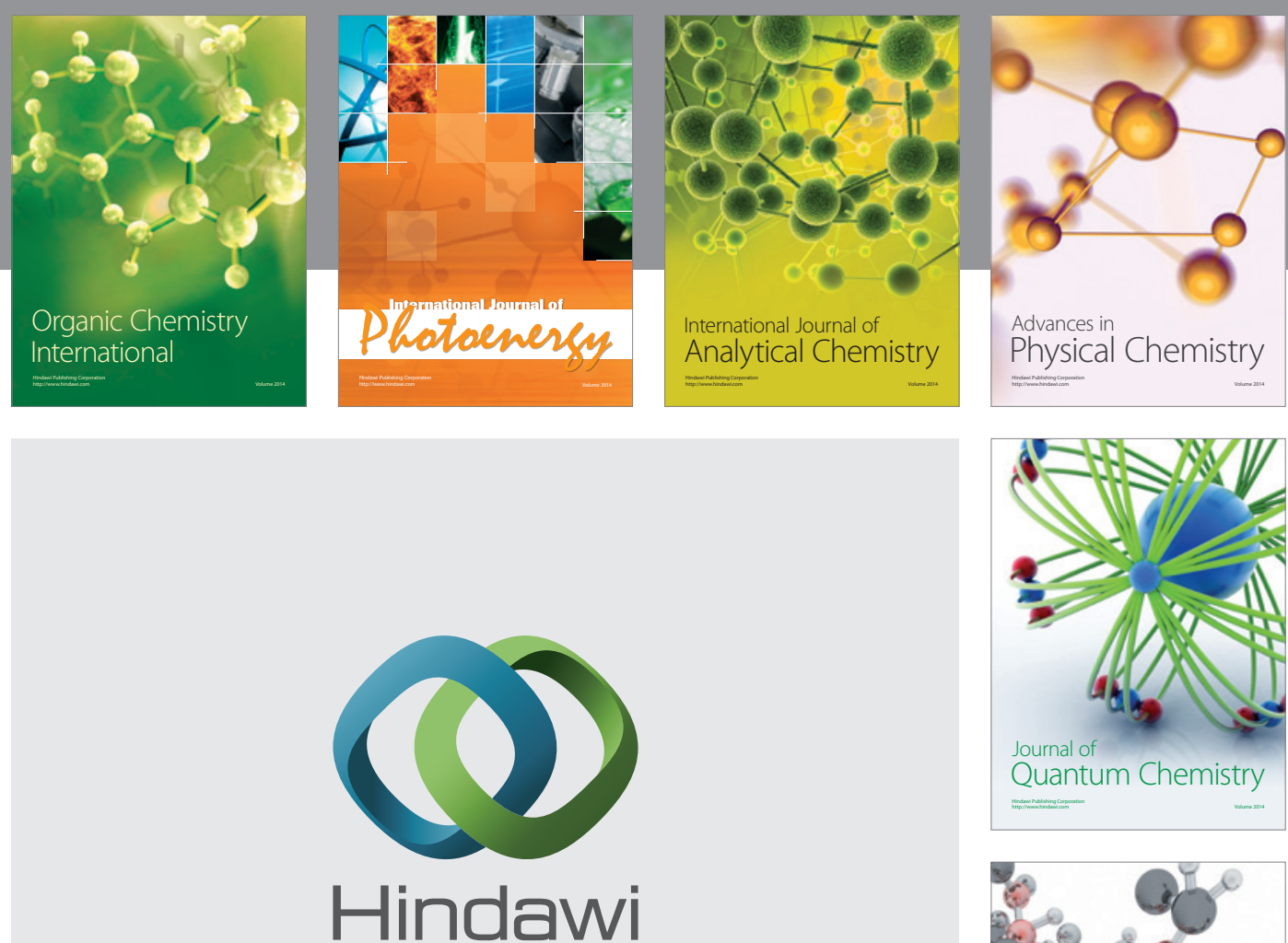

Submit your manuscripts at

http://www.hindawi.com

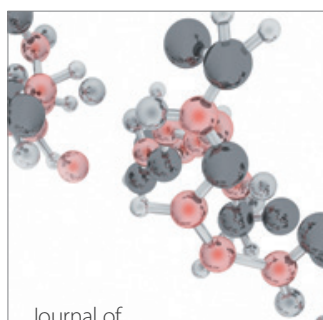

Analytical Methods

in Chemistry

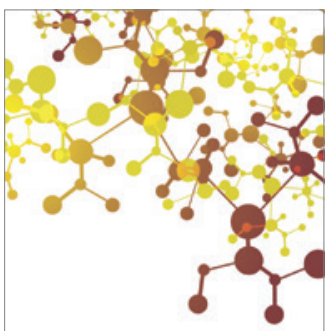

Journal of

Applied Chemistry

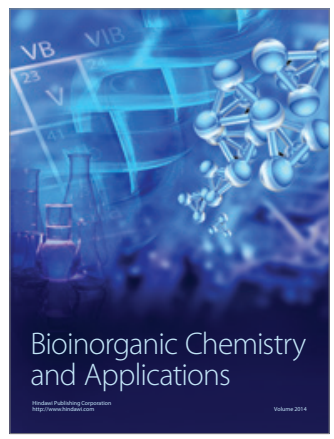

Inorganic Chemistry
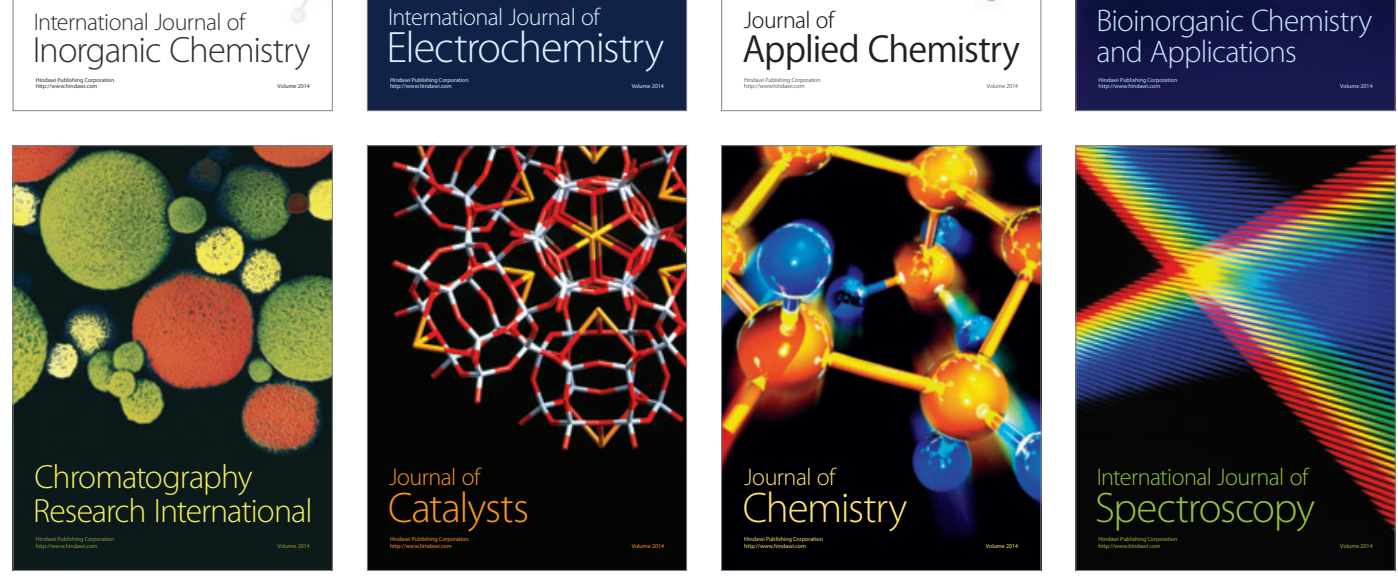